\section{Consumo de folato em gestantes de um hospital público do Rio de Janeiro *}

\section{Dietary folate intake by pregnant women in a public hospital in Rio de Janeiro}

\author{
Vania Matos Fonseca \\ Instituto de Medicina Social \\ Universidade do Estado do Rio de Janeiro \\ Rua São Francisco Xavier, 524 - $7 \circ$ andar - Bloco D \\ CEP 20550-900 - Maracanã - Rio de Janeiro, RJ \\ FIOCRUZ/Instituto Fernandes Figueira \\ Av. Rui Barbosa, 716 - Flamengo \\ CEP 22020-250 - Rio de Janeiro, RJ \\ vaniamf36@hotmail.com

\section{Rosely Sichieri} \\ Instituto de Medicina Social \\ Universidade do Estado do Rio de Janeiro

\section{Luciana Basilio} \\ Instituto de Medicina Social \\ Universidade do Estado do Rio de Janeiro

\section{Luciana Viana da Costa Ribeiro} \\ Instituto de Medicina Social \\ Universidade do Estado do Rio de Janeiro
}

\section{Resumo}

O folato tem importante papel na formação do DNA e RNA, aspecto central do desenvolvimento fetal. Há desconhecimento em relação ao folato ingerido durante a gravidez em gestantes brasileiras, mas uma significante proporção de mulheres em idade reprodutiva em outros países e em condições semelhantes consome dietas com baixos níveis de folato e não usa suplementos contendo ácido fólico. Examinou-se o consumo de folato em 285 gestantes de uma maternidade pública (Instituto Fernandes Figueira - FIOCRUZ) da cidade do Rio de Janeiro. O consumo alimentar de folato foi medido por um questionário semiquantitativo de freqüência de consumo alimentar, previamente validado, com porções padronizadas por alimento. Foram coletados dados sobre características demográficas, socioeconômicas e uso de ácido fólico como suplemento medicamentoso na gestação. A prevalência de deficiência de folato na dieta (ingestão abaixo de $600 \mu \mathrm{g} / \mathrm{dia}$ ) foi de $51,3 \%$. Somente $22,4 \%$ das gestantes fizeram uso de suplemento medicamentoso contendo ácido fólico. Adicionando-se o suplemento ao folato da dieta, esta prevalência caiu para $43,8 \%$. Mulheres com menores renda consomem mais energia, mais folato e usam mais ácido fólico como suplemento. Os alimentos que explicaram a variação no consumo de folato foram carne bovina, $\mathrm{R}^{2}=0,962(\mathrm{p}=$ $0.02)$, e leite, $R^{2}=0,038(p=0,007)$. Dada a necessidade de suplementação de folato durante a gravidez, sugerimos como importante medida $o$ aconselhamento para iniciarse a ingestão de suplemento de ácido fólico nas mulheres que planejam engravidar, e o reforço da importância da sua indicação nas consultas médicas pré-concepcionais e de pré-natal.

Palavras-chave: Folato. Ácido fólico. Prevalência de deficiência de folato em gestantes. Suplemento de ácido fólico.

* Pesquisa financiada pela Organización Panamericana de la Salud (registro: HDP/HDR/RG - T/ BRA/3143) 
Abstract

Folate plays an important role in DNA and RNA synthesis, a central feature of fetal development. There is a lack of information concerning dietary folate intake during pregnancy in Brazil, and in other countries, a significant proportion of women in childbearing age have low dietary folate intake and do not use folic acid-containing supplements. Folate intake by pregnant women was examined in a public hospital in the city of Rio de Janeiro. The analysis included 285 pregnant women at the Fernandes Figueira Institute Maternity (FIOCRUZ). Food-derived folate was assessed by a semi-quantitative food frequency questionnaire, previously validated, with standardized food portions. The study collected data on demographic and socio-economic characteristics and the use of folic acid supplements throughout pregnancy. The prevalence of a deficient dietary folate intake (intake $<600 \mu \mathrm{g} /$ day) was of $51.3 \%$. Only $22.4 \%$ of the pregnant women used folic acid supplements. With the inclusion of supplemental folate in the dietary folate intake, the prevalence dropped to $43.8 \%$. Low-income women reported greater intake of energy, folate and folic acid supplements. The variation of folic consumption was explained by beef, $R^{2}=0.962(p=0.02)$, and milk, $R^{2}=0.038$ ( $p=0.007$ ). Due to the necessity of folate supplementation during pregnancy, we suggest it is important to advise women planning to conceive to start the use of folic acid supplements, as well as the emphasis.

Key Words: Folate. Folic acid. Prevalence of deficient dietary folate intake by pregnant women. Folic acid supplements.

\section{Introdução}

Folato é um termo genérico para os compostos que têm atividade vitamínica similar a do ácido pteroilglutâmico ${ }^{1}$. O termo é usado tanto para as formas da vitamina, que ocorrem naturalmente nos alimentos, quanto para a forma sintética encontrada em suplemento medicamentoso e em alimento enriquecido $^{2}$. O folato age como coenzima em várias reações celulares fundamentais $\mathrm{e}$ é necessário na divisão celular devido ao seu papel na biossíntese de purinas e pirimidinas, e, conseqüentemente, na formação do DNA e do RNA. Em geral, o crescimento rápido e as multiplicações celulares, aspecto central do desenvolvimento fetal, requerem um suprimento adequado de folato ${ }^{1,3}$. Durante a gravidez, o folato interfere com o aumento dos eritrócitos, o alargamento do útero e o crescimento da placenta e do feto ${ }^{3}$. Baixa ingestão de folato na gravidez e baixas concentrações de folato materno podem acarretar anemia megaloblástica, parto prematuro e baixo peso ao nascer ${ }^{4}$.

Embora a redução na incidência de defeitos do tubo neural esteja inequivocamente ligada à adequação da ingestão de folato, e existam evidências da associação entre folato e outras malformações fetais, tem sido sugerido que o nível de folato pode ser em parte controlado pela genética do indivíduo, e ainda envolver um efeito "coquetel" resultante das interações entre genes, nutrientes e enzimas ${ }^{5}$. Se a suscetibilidade genética pode ser estabelecida, a possibilidade de desenvolvimento de testes para identificar mulheres de alto risco pode se tornar uma opção defensável. Contudo, para uma política de saúde pública, os custos e a efetividade do enriquecimento dos alimentos com ácido fólico indicam que este seria o caminho mais adequado ${ }^{6}$.

Estudos metabólicos apontam que a ingestão dietética de $600 \mu \mathrm{g} /$ dia de folato mantém uma concentração normal de folato nas células vermelhas, sendo portanto adequado para garantir um nível normal de folato em mulheres grávidas ${ }^{2}$. Embora haja falta de informação no que diz respeito ao 
folato ingerido durante a gravidez em mulheres brasileiras, sabe-se que uma significante proporção de mulheres em idade reprodutiva e em condições sociais semelhantes consome dietas com baixos níveis de folato e não usa suplementos contendo ácido fólico ${ }^{3}$.

No Brasil, encontramos um estudo que foi realizado no Rio de Janeiro com 74 gestantes e nutrizes, e que observou uma prevalência de $80 \%$ de mulheres com ingestão abaixo do recomendado ${ }^{7}$.

Estudo populacional americano apontou que somente $10 \%$ das mulheres grávidas alcançaram a recomendação proposta pela RDA (Recommended Dietary Allowance) para o folato ${ }^{8}$. A prevalência de deficiência de folato (eritrócito) em mulheres indianas em diferentes estágios da gravidez situa-se entre $40,5 \%$ e $53,3 \%^{1}$. Entre as chinesas em idade fértil, a deficiência bioquímica de ácido fólico é de $23 \%^{9}$, e no mesmo grupo de mulheres alemãs esta taxa é de $25 \%^{10}$.

Condições sócio-econômicas desfavoráveis estão associadas à deficiência de folato. Além disso, fatores como ser negra, solteira, ter menos de 20 anos e escolaridade menor que o $2^{\text {o }}$ grau $^{11}$ aparecem como preditores associados ao uso irregular de suplementos durante a gravidez em mulheres americanas. Fatores comportamentais como fumo também podem estar relacionados à deficiência de folato ${ }^{12}$.

Dada a falta de informação sobre a prevalência de deficiência de folato na população em geral, em nosso país, e especialmente no grupo das gestantes, formulou-se o presente estudo para determinação da prevalência de deficiência de folato em uma população de mulheres usuárias de um serviço de referência de atendimento para gravidez de risco, e para avaliar os fatores associados ao consumo de folato na dieta e nos suplementos.

\section{Metodologia}

A população deste estudo faz parte de um estudo caso-controle de crianças prematuras (casos) nascidas no Instituto
Fernandes Figueira (FIOCRUZ), RJ, no período de julho de 2000 a abril de 2001, e das crianças a termo (controles) nascidas em três dias da semana. Crianças prematuras são aquelas com idade gestacional $<37$ semanas. O Instituto é uma instituição de ensino, pesquisa e assistência que se caracteriza pelo atendimento de referência a gestantes e recém-nascidos de risco.

Das 328 parturientes que compunham esta população, 37 não aceitaram participar da pesquisa.

O consentimento para a participação na pesquisa foi solicitado à gestante entre $24 \mathrm{e}$ 48 horas depois do parto e após esclarecimentos sobre o conteúdo e os objetivos da pesquisa. O projeto foi aprovado pelo Comitê de Ética Médica em Pesquisa do IFF, em 22 de maio de 2000.

Para as mães que assinaram o termo de consentimento foram realizadas entrevistas por um único pesquisador, previamente treinado, tendo sido coletados dados sobre a sua prática alimentar durante a gestação, história patológica pregressa naquela gravidez e situação socioeconômica familiar atual, idade, escolaridade, estado civil, número de pessoas residentes na casa, renda $\mathrm{e}$ etnia. E ainda o uso de ácido fólico como suplemento medicamentoso no primeiro, segundo e terceiro trimestres da gestação.

Posteriormente, o mesmo pesquisador coletava e conferia a idade gestacional registrada em prontuário.

Para estimar a prevalência do consumo de folato foram feitas ponderações, corrigindo para o fato de que as crianças a termo representam 3/7 do total de crianças. Assim sendo, atribuiu-se peso de 0,63 para os prematuros e 1,337 para os bebês a termo, respeitando assim o número total de mães selecionadas para o estudo, 291. Destas, foram retiradas seis mães por apresentarem ingestão calórica superior a $5000 \mathrm{Kcal}$, por ser pouco provável nesta população o consumo de folato da dieta superior a $1700 \mu \mathrm{g}$ / dia, totalizando finalmente 285 participantes, sendo 136 mães de prematuros e 149 mães de crianças a termo. O consumo de folato foi avaliado através de um questioná- 
rio semiquantitativo de freqüência de consumo alimentar (QFC), contendo 80 itens e previamente validado por Sichieri ${ }^{13}$ para várias vitaminas, mas não ácido fólico, e estruturado com porções padronizadas para cada alimento. Como as principais fontes de folato encontram-se no questionário, é de se considerar que o mesmo possa também ser válido para avaliação de folato.

O cálculo da quantidade de folato presente nos alimentos foi feito utilizando-se a Tabela de Composição de Alimentos do Departamento de Agricultura dos Estados Uni$\operatorname{dos}^{14}$. Para estimar a quantidade de ácido fólico diário proveniente do suplemento considerou-se a utilização por trimestres. Se a gestante afirmasse ter utilizado os três trimestres, assumia-se um consumo diário de 0,4 mg, pois, segundo o $\mathrm{DEF}^{15}$, esta é a dose recomendada para as gestantes, e usual nos suplementos vitamínicos consumidos pelas gestantes. Se as gestantes referiam o uso somente num trimestre, estimou-se a quantidade diária em 0,4/3; se em dois, 0,4*2/3. Foi realizada análise do folato plasmático numa amostra de 60 mulheres do estudo: as que declararam fazer uso de suplemento tinham o dobro de folato em relação àquelas que declaram o não uso, sugerindo assim confiabilidade nas informações coletadas.

Na verificação da adequação do consumo de folato na gravidez, utilizou-se como referência a recomendação preconizada pelo Institute of Medicine (Food and Nutrition Board) da National Academy of Sciences ${ }^{16}$, que considera como deficiente a ingestão abaixo de $600 \mu \mathrm{g} / \mathrm{dia}$. Adicionalmente, utilizamos também o proposto por School et al. ${ }^{4}$, com base na proposta da Recommended Dietary Allowance $(\mathrm{RDA})^{17}$, que considerava a ingestão de folato $<=60 \%$ do recomendado como baixa; e de $61 \%$ até $100 \%$ como intermediária. Foram adotadas na avaliação dos resultados deste trabalho as categorias sugeridas por estes autores, porém atualizadas para a recomendação recente acima citada. Assim, as categorias de consumo adotadas foram: baixa (<=360 $\mu \mathrm{g} / \mathrm{dia})$, intermediária (361-599 $\mu \mathrm{g} / \mathrm{dia})$, média (600-800 $\mu \mathrm{g}$ / dia) e acima da média ( $>800 \mu \mathrm{g} / \mathrm{dia}$ ).
Os bancos de dados foram construídos no sofware EPI INFO (Dean et al., 1990) ${ }^{18}$.

Através do Programa SAS (Statistical Analysis System ${ }^{19}$ foram construídas tabelas de freqüência mostrando a distribuição das variáveis estudadas. Na análise estatística foram utilizados os testes " $t$ "de student, qui-quadrado e Anova para as comparações dos níveis de consumo de energia, fontes de folato e renda, segundo categorias de ingestão total de folato e nas comparações das características maternas segundo uso de suplemento.

O programa usado para os cálculos de nutrientes do questionário semiquantitativo de freqüência de consumo alimentar (QFC) foi elaborado no SAS.

\section{Resultados}

A prevalência de deficiência de folato (ingestão abaixo de $600 \mu \mathrm{g} / \mathrm{dia}$ ) na dieta foi de $51,3 \%$. Somente $22,4 \%$ das gestantes fizeram uso de suplemento medicamentoso contendo ácido fólico. Quando este suplemento foi adicionado ao folato da dieta, esta prevalência caiu para $43,8 \%$.

Não houve diferença, segundo renda per capita, entre as gestantes que usaram suplemento. O uso de suplemento foi menor entre as gestantes brancas, $19,1 \%$, do que entre as de outras etnias (negra, mulata e amarela), 24,8\%, ( $p=0,25$ ) (Tabela 1). Quando se avaliou a ingestão total de folato (dieta + medicamento), categorizada por faixas de consumo, a situação de menor ingestão ocorreu entre as mulheres com renda per capita um pouco maior. As gestantes com consumo total de folato abaixo do ponto de corte proposto, $600 \mu \mathrm{g} / \mathrm{dia}$, tinham renda per capita de 1,9 (DP = 2.2) salário-mínimo $(\mathrm{SM})$, contra aquelas acima da faixa de deficiência, 1,6 (DP = 1.5) SM, p = 0.22 (Tabela 2).

Não foram encontradas diferenças significantes nas comparações entre as faixas de consumo de folato segundo as categorias das variáveis socioeconômicas (Tabela 3 ).

Os alimentos fontes de folato mais consumidos foram abacate, beterraba e couveflor. Além de pertencerem aos grupos das 
Tabela 1 - Uso de ácido fólico medicamentoso durante a gestação segundo características maternas, Instituto Fernandes Figueira (FIOCRUZ), RJ, 2000-2001.

Table 1 - Use of folic acid supplements and characteristics of pregnant women, Instituto Fernandes Figueira (FIOCRUZ), RJ, 2000-2001.

\begin{tabular}{|c|c|c|c|}
\hline Características Maternas & $\begin{array}{l}\text { Não usou suplemento } \\
\text { de ácido fólico } \\
(n=221)\end{array}$ & $\begin{array}{l}\text { Usou suplemento } \\
\text { de ácido fólico } \\
\qquad(\mathrm{n}=63)\end{array}$ & p-valor* \\
\hline Renda per capita em SM (233) & $1,8(\mathrm{DP}=1,9)$ & $1,5(\mathrm{DP}=1,1)$ & $\mathrm{p}=0,25$ \\
\hline \multicolumn{4}{|l|}{ Etnia (\%) } \\
\hline Branca $(n=131)$ & 80,9 & 19,1 & \\
\hline Negra, mulata e amarela $(n=150)$ & 75,2 & 24,8 & $p=0,25$ \\
\hline \multicolumn{4}{|l|}{ Escolaridade (\%) } \\
\hline $1^{\circ}$ grau $(n=133)$ & 80,3 & 19,7 & \\
\hline $2^{\circ}$ grau ou mais $(n=145)$ & 74,1 & 25,9 & $p=0,21$ \\
\hline \multicolumn{4}{|l|}{ Idade (\%) } \\
\hline$<18$ anos $(\mathrm{n}=49)$ & 83,9 & 16,1 & \\
\hline $18-35$ anos $(n=182)$ & 76,5 & 23,5 & \\
\hline$>35$ anos $(n=53)$ & 75,5 & 24,5 & $p=0,49$ \\
\hline
\end{tabular}

Tabela 2 - Categorias de ingestão total de folato durante a gravidez, Instituto Fernandes Figueira (FIOCRUZ), RJ, 20002001.

Table 2 - Total folate intake during pregnancy, Instituto Fernandes Figueira (FIOCRUZ), RJ, 2000-2001.

\begin{tabular}{|c|c|c|c|c|c|c|c|c|}
\hline \multirow{3}{*}{$\begin{array}{l}\text { Consumo e } \\
\text { características } \\
\text { das pacientes }\end{array}$} & \multicolumn{8}{|c|}{ Ingestão total de folato } \\
\hline & \multicolumn{2}{|c|}{$\leq 360 \mathrm{mg} / \mathrm{dia}$} & \multicolumn{2}{|c|}{ 361-599 mg/dia } & \multicolumn{2}{|c|}{$600-800 \mathrm{mg} / \mathrm{dia}$} & \multicolumn{2}{|c|}{$>800 \mathrm{mg} / \mathrm{dia}$} \\
\hline & Média & $\begin{array}{l}\text { Desvio- } \\
\text { padrão }\end{array}$ & Média & $\begin{array}{l}\text { Desvio- } \\
\text { padrão }\end{array}$ & Média & $\begin{array}{l}\text { Desvio- } \\
\text { padrão }\end{array}$ & Média & $\begin{array}{l}\text { Desvio- } \\
\text { padrão }\end{array}$ \\
\hline $\begin{array}{l}\text { Energia* } \\
\text { (Kcal/dia) } n=285\end{array}$ & 1598 & 567 & 1877 & 699 & 2454 & 999 & 3196 & 1334 \\
\hline $\begin{array}{l}\text { Folato dos alimentos } \\
(\mathrm{mg} / \mathrm{dia})^{*} \mathrm{n}=285\end{array}$ & 272,3 & 70,1 & 447,8 & 93,7 & 645,1 & 110,4 & 999,2 & 164,1 \\
\hline $\begin{array}{l}\text { Folato medicamentoso } \\
(\mathrm{mg} / \mathrm{dia})^{*} \mathrm{n}=60\end{array}$ & 133,3 & $\leq$ & 194,9 & 69,2 & 195,5 & 85,3 & 226,3 & 102,6 \\
\hline Renda per capita (SM) & 2,0 & 1,7 & 1,9 & 2,3 & 1,9 & 1,5 & 1,5 & 1,5 \\
\hline
\end{tabular}

*Significantemente diferente dos outros grupos $p$-valor $<0.0001 /{ }^{*}$ Significantly different from other intake groups, $p$-value of linear trend $p<0.0001$. $\leq=$ sem valor de desvio padrão DP, apenas 1 pessoa nesta categoria/ $\leq=$ with no standard deviation value, only one person in the group.

frutas e das hortaliças, freqüentemente ricos em folato, são mais baratos e populares, explicando assim a maior freqüência de consumo de folato entre as mulheres com renda per capita menor.

Os alimentos que melhor explicaram a variação no consumo de folato foram carne bovina, $\mathrm{R}^{2}=0.962(\mathrm{p}=0.02)$, e consumo médio diário de $31 \mathrm{~g}(\mathrm{DP}=36)$; e leite, $\mathrm{R}^{2}=$ $0.038(\mathrm{p}=0.007)$, consumo médio diário de $210 \mathrm{ml}(\mathrm{DP}=178)$ (Tabela 4$)$, totalizando um $\mathrm{R}^{2}$ acumulado $=1.00$.

Observou-se uma relação direta entre consumo energético, ingestão de folato e renda. As mulheres com menores rendas consomem mais energia, mais folato e usam 
Tabela 3 - Características das pacientes segundo categorias de ingestão de folato, Instituto Fernandes Figueira (FIOCRUZ), RJ, 2000-2001.

Table 3 - Factors associated with total folate intake during pregnancy, Instituto Fernandes Figueira (FIOCRUZ), RJ, 2000-2001.

\begin{tabular}{|c|c|c|c|c|}
\hline \multirow[b]{2}{*}{ Características das pacientes } & \multicolumn{4}{|c|}{ Ingestão total de folato } \\
\hline & $\begin{array}{c}\leq 360 \\
\mu \mathrm{g} / \mathrm{dia}\end{array}$ & $\begin{array}{c}\text { 361-599 } \\
\mu \mathrm{q} / \mathrm{dia}\end{array}$ & $\begin{array}{c}600-800 \\
\mu \mathrm{q} / \mathrm{dia}\end{array}$ & $\begin{array}{c}>800 \\
\mu \mathrm{q} / \mathrm{dia}\end{array}$ \\
\hline \multicolumn{5}{|l|}{ Idade $(n=284)$} \\
\hline$<18$ anos & 6,7 & 32,1 & 32,2 & 29,0 \\
\hline $18-35$ anos & 13,0 & 33,2 & 21,2 & 32,6 \\
\hline$>18$ anos & 13,6 & 27,2 & 15,9 & 43,3 \\
\hline \multicolumn{5}{|l|}{ Etnia $(n=282)$} \\
\hline Branca & 13,5 & 28,1 & 25,1 & 33,3 \\
\hline Outras & 10,0 & 35,7 & 20,1 & 34,2 \\
\hline \multicolumn{5}{|l|}{ Fumo $(n=283)$} \\
\hline Sim & 14,7 & 37,5 & 16,0 & 31,8 \\
\hline Não & 10,9 & 30,9 & 23,6 & 34,6 \\
\hline \multicolumn{5}{|l|}{ Estado civil $(n=280)$} \\
\hline Casada & 12,3 & 31,2 & 20,5 & 36,0 \\
\hline Solteira & 9,4 & 35,2 & 27,4 & 28,0 \\
\hline \multicolumn{5}{|l|}{ Escolaridade $(n=278)$} \\
\hline $1^{\circ} \mathrm{grau}$ & 14,4 & 34,6 & 19,1 & 31,9 \\
\hline $2^{\circ}$ grau ou mais & 9,4 & 30,0 & 23,6 & 37,0 \\
\hline \multicolumn{5}{|l|}{ Pessoas na casa $(n=272)$} \\
\hline 1-5 pessoas & 13,2 & 33,0 & 21,6 & 32,2 \\
\hline 6-9 pessoas & 0 & 27,9 & 20,5 & 51,6 \\
\hline
\end{tabular}

* Número total de mulheres inferior ao total do estudo em alguns itens devido a não resposta.

* In some items, the total number of women is lower than the total of the study due to non response.

Tabela 4 - Freqüência de consumo dos principais alimentos fonte de folato consumidos pelas gestantes, Instituto Fernandes Figueira (FIOCRUZ), RJ, 2000-2001.

Table 4 - Intake of major folate-rich foods consumed by pregnant women, Instituto Fernandes Figueira (FIOCRUZ), RJ, 2000-2001.

\begin{tabular}{|c|c|c|c|c|c|c|c|c|c|}
\hline \multirow[b]{2}{*}{ Alimento } & \multirow[b]{2}{*}{ Porção } & \multirow[b]{2}{*}{$\begin{array}{l}\text { Folato } \\
(\mathrm{mg}) / \\
\text { porção }\end{array}$} & \multirow[b]{2}{*}{$\begin{array}{l}\text { Média de } \\
\text { consumo } \\
\text { diário de } \\
\text { alimento }\end{array}$} & \multirow[b]{2}{*}{$\begin{array}{l}\text { Desvio- } \\
\text { padrão }\end{array}$} & \multicolumn{5}{|c|}{ Freqüência de Consumo } \\
\hline & & & & & $\begin{array}{c}\text { Pelo menos } \\
1 \text { vez por } \\
\text { dia }\end{array}$ & $\begin{array}{c}2 \text { a } 6 \\
\text { vezes } \\
\text { por } \\
\text { semana }\end{array}$ & $\begin{array}{c}1 \text { vez } \\
\text { por } \\
\text { semana }\end{array}$ & $\begin{array}{c}1 \text { a } 3 \\
\text { vezes } \\
\text { por mês }\end{array}$ & $\begin{array}{c}\text { Nunca ou } \\
\text { quase } \\
\text { nunca }\end{array}$ \\
\hline Feijão & $80 \mathrm{~g}$ & 119,1 & 126 & 97 & 68,0 & 25,0 & 0,7 & 2,6 & 3,7 \\
\hline Abacate & $75 \mathrm{~g}$ & 50,26 & 7 & 63 & 1,6 & 2,8 & 4,4 & 3,2 & 88,0 \\
\hline Laranja & $180 \mathrm{~g}$ & 54,00 & 279 & 395 & 22,9 & 33,5 & 9,3 & 15,2 & 19,1 \\
\hline $\begin{array}{l}\text { Suco de fruta } \\
\text { cítrica }\end{array}$ & $165 \mathrm{ml}$ & 49,23 & 253 & 316 & 43,7 & 36,2 & 2,1 & 10,2 & 7,8 \\
\hline Batata & $30 \mathrm{~g}$ & 6,72 & 11 & 18 & 2,8 & 27,1 & 16,3 & 24,5 & 29,3 \\
\hline Couve & $60 \mathrm{~g}$ & 8,57 & 6 & 17 & 2,3 & 9,2 & 11,8 & 15,5 & 61,2 \\
\hline Couve-flor & $150 \mathrm{~g}$ & 26,61 & 5 & 23 & 0,5 & 2,0 & 3,8 & 11,1 & 82,6 \\
\hline Tomate & $165 \mathrm{ml}$ & 21,95 & 70 & 105 & 21,0 & 35,2 & 10,8 & 11,8 & 21,2 \\
\hline Leite & $60 \mathrm{~g}$ & 8,11 & 210 & 178 & 67,9 & 12,0 & 3,3 & 4,6 & 12,2 \\
\hline Carne bovina & $50 \mathrm{~g}$ & 5,65 & 31 & 36 & 5,7 & 64,1 & 9,7 & 9,6 & 10,9 \\
\hline Fígado & $50 \mathrm{~g}$ & 110,8 & 9 & 19 & 0,9 & 14,5 & 14,0 & 26,3 & 44,3 \\
\hline
\end{tabular}


Tabela 5 - Consumo de energia e folato segundo renda per capita em salário mínimo (SM), Instituto Fernandes Figueira (FIOCRUZ), RJ, 2000-2001.

Table 5 - Energy and folate intake and per capta income in minimum wages (SM), Instituto Fernandes Figueira (FIOCRUZ), RJ, 2000-2001.

\begin{tabular}{lccccc}
\hline & \multicolumn{2}{c}{$\leq 1 \mathrm{SM}(\mathrm{n}=146)$} & \multicolumn{2}{c}{$>$ SM $(\mathrm{n}=59)$} & \\
\cline { 2 - 5 } & Média & $\begin{array}{c}\text { Desvio- } \\
\text { padrão }\end{array}$ & Média & $\begin{array}{c}\text { Desvio- } \\
\text { Padrão }\end{array}$ & p-valor \\
\hline Energia (Kcal/dia) & 2594 & 1251 & 2284 & 1044 & 0,09 \\
Folato dos alimentos (mg/dia) & 693,3 & 319,3 & 596,4 & 315,8 & 0,04 \\
$\begin{array}{lllll}\text { Folato dos alimentos + } \\
\text { suplemento ( } \mu \mathrm{g} / \text { dia) }\end{array}$ & 741,6 & 329,5 & 630,3 & 318,6 & 0,02 \\
\hline
\end{tabular}

mais ácido fólico como suplemento medicamentoso (Tabela 5).

Além disso, a média de ingestão energética foi ligeiramente maior nas mulheres não brancas ( $2479 \mathrm{kcal})$ do que entre as brancas (2396 kcal), $\mathrm{p}=0.56$. A média geral de energia das gestantes foi de $2440 \mathrm{kcal}(\mathrm{DP}=1192)$.

\section{Discussão}

À semelhança do que tem sido observado em outros países ${ }^{3}$, uma significante proporção de mulheres em idade reprodutiva no presente estudo apresentou baixa ingestão de folato, tanto na dieta, quanto nos suplementos. Observamos que somente $22,4 \%$ das gestantes usaram ácido fólico como suplemento e, ao contrário dos Estados Unidos ${ }^{20}$, não encontramos associação com a cor da pele.

Dados do inquérito nacional americano (NHANESII) apontaram que somente $10 \%$ das mulheres grávidas alcançaram a recomendação proposta pela RDA para o folato ${ }^{8}$. No presente estudo, encontrou-se aproximadamente $50 \%$ das gestantes nesta situação. A freqüência de consumo de feijão, uma das importantes fontes de folato entre nós, poderia explicar as diferenças observadas em relação às mulheres americanas. Dificuldade em atingir a quantidade de folato recomendada foi também relatada para a população alemã. Assim, em pesquisa de base populacional com 4030 participantes, entre 19 e 79 anos, somente um terço alcançou a recomendação. Quando os participantes referiram suplementação específica para o folato, esta proporção aumentou para $50 \%{ }^{21}$. O hábito alimentar brasileiro mais tradicional, com predominância de feijão e carne, talvez permita uma mais adequada ingestão de folato, como foi observado para as mulheres de menores rendas. Mulheres americanas que foram avaliadas quanto ao consumo alimentar por quatro dias não consecutivos ${ }^{3}$ referiram que quase não comiam feijão, e as de baixa renda comiam poucos vegetais. Metade das mulheres referiram que não comiam nenhum vegetal, incluindo batata.

Estudo realizado com adolescentes nigerianas mostrou que elas consumiam somente $28 \%$ do folato recomendado, sendo as fontes de folato os alimentos provenientes de três grupos: raízes e tubérculos, cereais e legumes ${ }^{22}$. Também na Índia, segundo dados de pesquisa nacional, a ingestão de folato, em mais de $60 \%$, foi oriunda de legumes, verduras e cereais.

Segundo Koebnick et al. ${ }^{23}$, mulheres que consomem dietas predominantemente vegetarianas a longo prazo possuem uma concentração maior dos níveis de folato plasmático e eritrocitário, reduzindo o risco de deficiência na gravidez. Mulheres com dietas vegetarianas, quando comparadas àquelas cuja dieta era tipicamente ocidental, apresentavam menor prevalência de déficit de folato. A prevalência de deficiência de folato foi de 7,5\% para as ovo-lacto vegetarianas, $13,8 \%$ para as com dieta predominantemente vegetarianas, e $29 \%$ para as que faziam uso de dieta ocidental. Nos nossos resultados, 
embora as maiores correlações entre ingestão de folato e consumo de alimentos tenham sido encontradas em vegetais, as diferenças nas variâncias de consumo de folato foram melhor explicadas pela carne bovina e o leite da dieta.

As gestantes cuja renda per capita situouse abaixo da linha de pobreza $(<=1$ salário mínimo), tiveram um significante aumento na ingestão de folato em relação àquelas com renda per capita superior a um salário mínimo, e outros autores encontraram maior ingestão de folato em mulheres de baixa renda ${ }^{24}$. A ingestão média de calorias das nossas gestantes foi de $2440 \mathrm{kcal}$, tendendo a ser maior no grupo de menor renda, embora as diferenças não tenham sido estatisticamente significantes ( $p=0,09$ ), e este valor foi bem próximo ao resultado encontrado por Siega-Riz et al. ${ }^{25}$, $2478 \mathrm{kcal}$ em mulheres americanas.

Dada a importância do ácido fólico durante a gestação na prevenção de defeitos ligados ao nascimento e complicações comuns à gravidez, tais como prematuridade, baixo peso ao nascer e anemia, os países ocidentais têm iniciado a implementação da fortificação de alimentos como uma maneira custo-efetiva para reduzir os efeitos adversos da deficiência de folato ${ }^{16,26}$.

Uma combinação de dieta rica em alimentos com folato e suplementação de ácido fólico seria a recomendação adequada para prevenir a deficiência de folato. Identificamos que as mulheres acima de um salário-mínimo per capita consomem menos folato e menos calorias, sugerindo que mulheres com dietas menos calóricas devam ser orientadas para aumentar o consumo de alimentos com folato. Tem também sido sugerido o aconselhamento para iniciar ou continuar a ingestão de suplemento de ácido fólico para mulheres que planejam engravidar, nas consultas médicas préconcepcionais, o que parece promover a adesão a esta medida ${ }^{27}$.

A fortificação, entretanto, é considerada a medida mais importante de saúde coletiva, pois as alterações no tubo neural ocorrem nas primeiras semanas de gestação, antes mesmo que a mulher procure um serviço de pré-natal.

A fortificação de alimentos com ácido fólico foi implementada por vários países, como o Canadá, que reduziu a prevalência de defeitos do tubo neural de 1,13 por 1000 gestações para 0,58 por 1000 , após a adição de 0,1-0,2 mg de folato por dia na dieta da população canadense através dos produtos à base de grãos de cereais ${ }^{28}$.

No Brasil, o Ministério da Saúde, através da Agência Nacional de Vigilância Sanitária (ANVISA), regulamentou a partir de maio de 2002 a adição de 100 microgramas de ácido fólico para cada 100 gramas de farinha de trigo e milho, além dos produtos derivados do milho comercializados no Brasil, o que deve reduzir a prevalência de deficiência que encontramos.

\section{Agradecimentos}

Agradeço à epidemiologista Dr ${ }^{\mathrm{a}}$ Kátia Silveira da Silva pelas importantes contribuições.

\section{Referências}

1. Krishnaswamy K, Nair KM, Importance of folate in human nutrition. Br J Nutr 2001; 85: S115-S24.

2. Bailey LB. New standard for dietary folate intake in pregnant women. J Clin Nutr 2000; 71: 1304S-7S.

3. Scholl TO, Johnson WG. Folic acid: influence on the outcome of pregnancy. Am J Clin Nutr 2000; 71: 1295S$303 S$.

4. Scholl TO, Hediger ML, Schall JI, Khoo CS, Fischer RL.Dietary and serum folate: their influence on the outcome of pregnancy. Am J Clin Nutr 1996; 63: 520-5.
5. Moyers S, Bailey LB. Fetal malformations and folate metabolism: review of recent evidence. Nutr Rev 2001; 59 (7): 215-24.

6. Feinleib M, Beresford SAA, Bowman BA, Mills JL, Rader JI, Selhub J, et al. Folate fortification for the prevention of Birth defects: case study. Am J Epidemiol 2001; 154 (12): S60-S9.

7. Trugo NMF. Micronutrient regulation in pregnant and lactating women from Rio de Janeiro. Arch Latinoam Nutr 1997; 47 (S.1): 30-4. 
8. Subar AF, Block G. Use of vitamin and mineral supplements: demographics and amounts of nutrients consumed (The 1987 Health Interview Survey.). Am J Epidemiol 1990; 133: 1091-101.

9. Ronnenberg AG, Goldman MB, Aitken IW, Xu X. Anemia and deficiencies of folate and vitamin B-6 are common and vary with season in Chinese women of childbearing age. J Nutr 2000; 130(11): 2703-10.

10. Gonzalez-Gross M, Prinz-Langenohl R, Pietrzik K. Folate status in Germany 1997-2000. Int J Nutr Res 2002; 72(6): 351-9.

11. Yu SM, Keppel KG, Singh GK, Kessel w. Preconceptional and prenatal multivitamin-mineral supplement use in the 1988 National Maternal and Infant Health Survey. American Journal Public Health 1996; 86: 240-2.

12. Benedich A. Importance of vitamin status to pregnancy outcomes. In: Benedich A, Butterworth CE Jr, eds. Micronutrients in health and in disease prevention, New York: Marcel Dekker Inc; 1991. p. 23562.

13. Sichieri, R, Estudo de validação do questionário de freqüência de consumo de alimentos. Epidemiologia da obesidade. Rio de Janeiro: EdUERJ; 1998. p. 25-34.

14. Nutrient database for standard reference, release 14 . United States Department of Agriculture; 2001.

15. Dicionário de especialidades farmacêuticas (DEF 2000/01). Jornal Brasileiro de Medicina; 1998.

16. Institute of Medicine, Food and Nutrition Board. Dietary reference intakes for thiamin, riboflavin, niacin, vitamin B6, folate, vitamin B12, Pantothenic acid, biotin, and choline, A report of the Standing Committee on the Scientific Evaluation of Dietary Reference Intakes and its Panel on Folate, other B vitamins, and Choline. Washington, DC: National Academy Press; 1998.

17. National Research Council. Recommended dietary allowances, $10^{\text {th }}$ ed, Washington, DC: National Academy Press; 1989.

18. Dean et al. Epi Info, version 6.04. Center for Disease Control, Atlanta, Georgia, USA, 1990.
19. SAS (Statistical Analysis System), SAS, Cary, NC, versão 8.1 .

20. Suitor CW, Gardner JD. Supplement use among a culturally diverse group of low-income pregnant adolescents. J Am Diet Assoc 1990; 90: 268-71.

21. Beitz R, Mensink GB, Fisher B, Thamn M. Vitaminsdietaty intake and intake from dietary supplements in Germany. Eur J Clin Nutr 2002; 56(6): 539-45.

22. Oguntona CR, Akinyele IQ. Food and nutrient intake by pregnant nigerian adolescents during the third trimester. Nutr 2002; 18 (7-8): 673-9.

23. Koebnick C, Heins UA, Hoffmann I, Dagnelie PC, Leitzmann C. Folate status during pregnancy in women is improved by long-term high vegetable intake compared with the western diet. J Nutr 2001; 131: 733-9.

24. Bodnar LM, Siega-Riz AM. A Diet Quality Index for Pregnancy detects variation in diet and differences by sociodemographic factors. Public Health Nutr 2002; 5(6):801-9.

25. Siega-Riz AM, Bodnar LM, Savitz DA. What are pregnant woman eating? Nutrient and food group differences by race. Am J Obstet Gynecol 2002; 181(3): 480-6.

26. Malinow MR, Duel PB, Hess DL, Anderson PH, Krunger $\mathrm{WD}$, Phillipson BE, et al. Reduction of plasma homocysteine levels by breakfast cereal fortified with folic acid in patients with coronary heart disease. New Engl J Med 1998; 338: 1009-15.

27. Weerd S, Thomas CMG, Cikot RJLM, SteegersTheunissen PM, Boo TM, Steergers EAP. Preconception counseling improves folate status of women planning pregnancy. Obstet Gynecol 2002; 99: 45-50.

28. Ray JG, Meier C, Vermeulen MJ, Boss S, Wyatt PR, Cole DE. Association of neural tube defects and folic acid food fortification in Canada. Lancet. 2002; 28; 360(9350):2047-8.

Recebido em: 28/08/2002 Versão final reapresentada em: 01/09/2003 Aprovação em: 05/09/2003 